\title{
A SIMPLE, FAST, AND INEXPENSIVE NON- CHROMATOGRAPHIC METHOD FOR THE ISOLATION OF PINOSTROBIN FROM Boesenbergia rotunda RHIZOME
}

\author{
N. Fakhrudin ${ }^{1,}$, O. Pramiastuti ${ }^{1,2}$ and W. Subagus ${ }^{1}$ \\ ${ }^{1}$ Faculty of Pharmacy, Universitas Gadjah Mada, Yogyakarta 55281, Indonesia \\ ${ }^{2}$ STIKes Bhakti Mandala Husada Slawi, Tegal 52416, Indonesia \\ ${ }^{\square}$ Corresponding Author: nanangf@ugm.ac.id
}

\begin{abstract}
Pinostrobin is a plant-derived natural compound with high pharmacological and economic value. Pinostrobin exhibits various biological activities and is widely distributed in plant species. In addition to its wide distribution, pinostrobin is the main chemical ingredient of Boesenbergia rotunda rhizome. To date, pinostrobin is obtained by direct isolation from its sources, mainly from the $B$. rotunda rhizome, by utilizing various chromatographic methods. However, these chromatography-based isolation methods are time-consuming, laborious, and expensive. This study aimed to provide a method to isolate pinostrobin from $B$. rotunda rhizome without utilizing chromatographic techniques. Dried powder of $B$. rotunda was macerated in petroleum ether. The liquid extract obtained was concentrated and stored at a temperature of $-20{ }^{\circ} \mathrm{C}$ for $18 \mathrm{~h}$ until pale yellow precipitates were formed. The precipitates were filtered and dissolved in warm methanol and stored at a temperature of $-20^{\circ} \mathrm{C}$ for $18 \mathrm{~h}$. The formed yellowish crystals were decanted, filtered, and washed with cold methanol $\left(4{ }^{\circ} \mathrm{C}\right)$ to obtain colorless pinostrobin crystals. The crystals were dried and weighed. The purity of the crystals was determined by high-performance liquid chromatography. Meanwhile, the chemical structure of the crystals was verified based on its infrared, ultraviolet, and nuclear magnetic resonance (i.e., ${ }^{1} \mathrm{H}-\mathrm{NMR}$, and ${ }^{13} \mathrm{C}-\mathrm{NMR}$ ) spectra. This study provides a "shortcut" method to isolate pinostrobin from $B$. rotunda rhizome, with a yield of $2.36 \%$ and purity of $\geq 99 \%$. This study provides a simple, fast, and inexpensive method to obtain pinostrobin without using chromatographic techniques.

Keywords: Purification, Identification, Chromatography, Boesenbergia rotunda, Fingerroot
\end{abstract}

RASĀYAN J. Chem., Vol. 14, No.2, 2021

\section{INTRODUCTION}

Pinostrobin is a flavonoid compound reported to have various pharmacological activities, such as antimicrobial, anticancer, antioxidant, anti-inflammatory, and neuroprotective. ${ }^{1}$ This compound has potent pharmacological activities and high economic value and is used as a marker compound for the quality control of herbal products containing Boesenbergia rotunda rhizome ${ }^{2}$. In addition to its various pharmacological activities, pinostrobin is widely distributed in plants, such as B. rotunda ${ }^{3}$, Cajanus cajan ${ }^{4}$, Alpinia zerumbet ${ }^{5}$, Piper ecuadorense ${ }^{6}$, and plants from the genus Populus. Pinostrobin is also found in honey $^{7}$ and bee propolis ${ }^{8}$. Among these sources of pinostrobin, B. rotunda rhizome has the most potential because it contains $2 \%$ to $3 \%$ of pinostrobin ${ }^{9}$. This plant is widely grown in South East Asia and traditionally used as a food seasoning and herbal remedies for the treatment of scurvy, colds, flatulence, constipation, lack of appetite, itching, heartburn, tuberculosis, allergies, cancer, leptospirosis, inflammation, ulcer, herpes, dengue, wounds, and hepatic diseases. ${ }^{10,11}$ B. rotunda is a member of the Zingiberaceae plant family that is rich in flavonoids. The flavonoid constituents are either prenylated forms, such as panduratin, hydroxypanduratin, isopanduratin, boesenbergin, hydroxyboesenbergin, geranylpinostrobin, geranylpinocembrin, krachaizin, and nicolaioidesin, or non-prenylated forms, such as cardamonin, pinostrobin, pinocembrin, helichrysetin, flavokawain $\mathrm{C}$, and uvangoletin. In addition, essential oil components, such as $\gamma$-terpinene, borneol, camphor, myrcene, geraniol, $\alpha$-ocimene, camphene, neral, geranial, terpineol, and methyl cinnamate, are present. ${ }^{11-13}$ Among these chemical constituents, the nonprenylated flavonoid pinostrobin is the major compound. ${ }^{9}{ }^{14}$ Different methods to isolate pinostrobin have been described in previous studies. However, all of those methods utilized chromatographic techniques, 
RASĀYAN J. Chem.

Vol. 14 | No. 2 |735-740| April - June | 2021

such as silica gel column chromatography, ${ }^{15,16}$ Sephadex LH-20 column chromatography, ${ }^{13}$ preparative thin-layer chromatography (TLC), ${ }^{17}$ gel-resin chromatography, ${ }^{18}$ flash column chromatography, ${ }^{19}$ and normal-phase silica gel medium-pressure column chromatography ${ }^{20}$ in their protocols. Consequently, the isolation and purification processes were time-consuming and laborious. The synthesis of pinostrobin has also been reported in several studies, but the yield is low. Although considerable progress has been achieved in terms of the stereoselective synthesis of pinostrobin, the difficulty in obtaining enantiomeric starting materials remains the main obstacle limiting its application. ${ }^{21}$ Thus, any effective and efficient method to obtain pinostrobin either from synthetic origins or natural resources is promising. This study aimed to develop a fast, simple, and inexpensive method to isolate pinostrobin from $B$. rotunda rhizome without utilizing chromatographic techniques.

\section{Plant Material}

\section{EXPERIMENTAL}

Boesenbergia rotunda rhizomes were obtained from Samigaluh District, Kulonprogo, Yogyakarta, Indonesia. The fresh rhizomes were washed with water, cut horizontally into small pieces (thickness of $0.2-$ $0.4 \mathrm{~mm}$ ), dried in an oven at $50{ }^{\circ} \mathrm{C}$ for $24 \mathrm{~h}$, and pulverized.

Extraction and isolation of pinostrobin

Dried powder of $B$. rotunda $(500 \mathrm{~g})$ was macerated in petroleum benzene $(2.5 \mathrm{~L})$ for $18 \mathrm{~h}$. The solvent was evaporated in a rotary evaporator and reused for the second maceration with the same procedure. After filtering, the liquid extracts obtained from the first and second maceration were combined and the solvent was evaporated in a rotary evaporator until approximately $100 \mathrm{~mL}$ of the solvent remained. This concentrated liquid extract was stored at a temperature of $-20{ }^{\circ} \mathrm{C}$ for $18 \mathrm{~h}$ until pale yellow precipitates were formed. The precipitates $(11.80 \mathrm{~g})$ were recrystallized by adding $50 \mathrm{~mL}$ of warm methanol $\left(60{ }^{\circ} \mathrm{C}\right)$ and stirring for $15 \mathrm{~min}$. The solution was stored in a freezer or at a temperature of $-20^{\circ} \mathrm{C}$ for $18 \mathrm{~h}$. The precipitates were filtered using filter paper attached to a glass funnel and washed with cold methanol $\left(4^{\circ} \mathrm{C}\right)$ several times until the yellowish crystals turned into colorless crystals. The colorless crystals $(4.41 \mathrm{~g})$ were left to dry at room temperature. This protocol is illustrated in Fig.-1.

\section{General Procedure}

To confirm the structure and identity of the isolated pinostrobin, the general procedures are as follows: The melting point was measured using the Reichert Kofler Thermopan (Reichert, Vienna, Austria). The infrared (IR) and ultraviolet (UV) spectra were recorded using the Shimadzu FTIR (Model 8201 PC) and Hitachi spectrophotometer (Model U-2900), respectively. The ${ }^{13} \mathrm{C}-\mathrm{NMR}$ and ${ }^{1} \mathrm{H}-\mathrm{NMR}$ spectra were recorded using the Jeol spectrometer (Model JNM-ECA) running at 400 and $100 \mathrm{MHz}$ for ${ }^{13} \mathrm{C}-\mathrm{NMR}$ and ${ }^{1} \mathrm{H}-\mathrm{NMR}$, respectively. The TLC analysis was performed on silica gel F254 using different mobile phases in a Camag TLC Chamber (Camag, Muttenz, Switzerland). The high-performance liquid chromatography (HPLC) analysis of pinostrobin was conducted using a photodiode array detector (PDA) at $254 \mathrm{~nm}$, with a manual injector, on a Waters Alliance e2695 HPLC instrument. The column is C18 XTerra $(5 \mu \mathrm{m}, 150 \mathrm{~mm} \times 780$ $\mathrm{mm}$ i.d.) in an isocratic system using the mobile phase of methanol/water (80:20), with sample injection of $20 \mu \mathrm{L}$ and flow rate of $1 \mathrm{~mL} / \mathrm{min}$.

\section{RESULTS AND DISCUSSION}

Pinostrobin is a plant-derived natural product with a wide range of biological activities. This pharmacologically active compound is present in various medicinal plants, such as Scutellaria violacea ${ }^{22}$ $(0.4 \%)$, Cajanus. cajan ${ }^{23}(0.5 \%)$, and plants from the genus Populus $(0.14 \%$ to $2.02 \%)$. Although widely distributed, pinostrobin is the main constituent of $B$. rotunda rhizome ${ }^{24}$, with a total content of $2 \%$ to $3 \%{ }^{9}$ The isolation of pinostrobin from plants has also been previously reported. However, the yield is still suboptimal and the process is laborious. Because B. rotunda rhizome is rich in pinostrobin, the isolation of pinostrobin from this rhizome needs to be optimized to obtain a high yield and economic value. This study developed a simple, fast, and inexpensive method to isolate pinostrobin from $B$. rotunda rhizome without utilizing chromatographic techniques. The scheme of pinostrobin isolation from $B$. rotunda rhizome is shown in Fig.-1.

Petroleum ether was the solvent of choice in the extraction process. The polarity and chemical properties of petroleum ether fulfilled the "like dissolves like" concept ${ }^{25}$ for pinostrobin extraction. Petroleum ether 
RASĀYAN J. Chem.

Vol. 14 | No. 2 |735-740| April - June | 2021

effectively extracted pinostrobin from plant bulk material. The economic value of petroleum ether warranted cost efficiency and solvent recoverability.

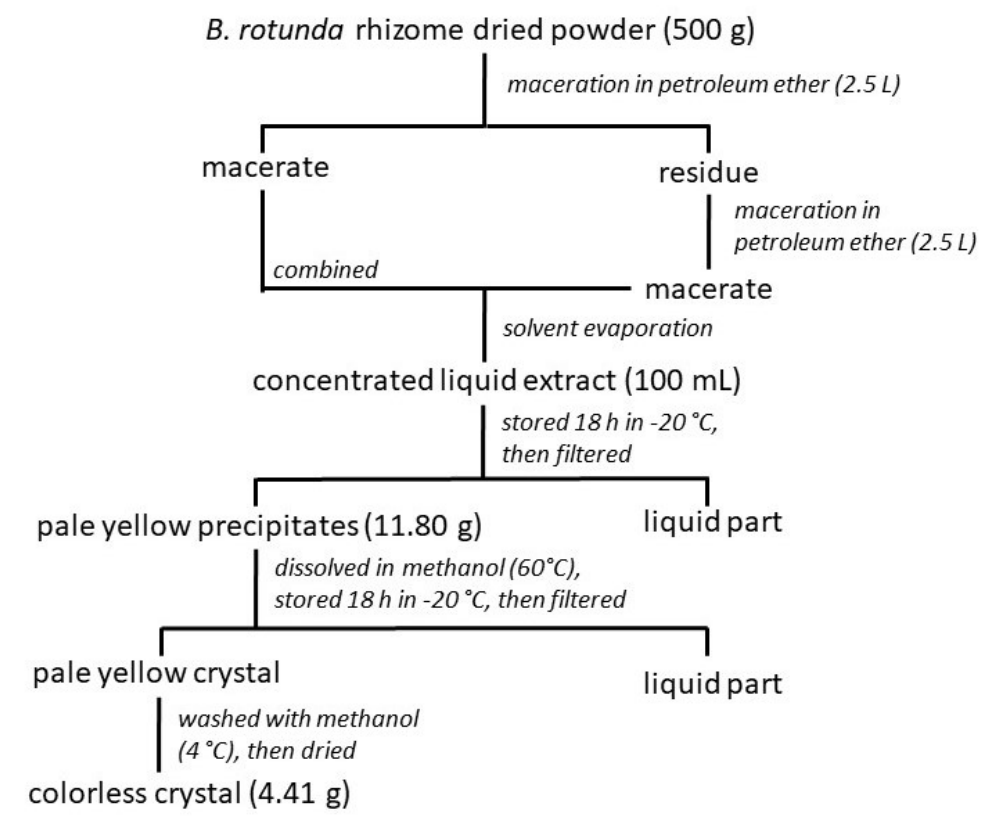

Fig.-1: Workflow of the Isolation of pinostrobin from B. rotunda rhizome without utilizing Chromatographic Techniques.

Pinostrobin is a compound in the flavonoid class that has a flavanone backbone with only one hydroxyl group (Fig.-2C). The lipophilic nature of pinostrobin ${ }^{26}$ makes it different from the other flavonoid-derived compounds present in $B$. rotunda rhizome, such as $2^{\prime}, 4^{\prime}$-dihydroxy-6'-methoxy chalcone, pinocembrin, helichrysetin, flavokawain C, uvangoletin, and 2',4-hydroxy-4',6'-dimethoxychalcone, which all have more than one hydroxyl group in their structures. Because of this feature, pinostrobin was effectively extracted with petroleum ether, whereas the others were less extractable. Consequently, the petroleum extract contained an abundant amount of pinostrobin. Pinostrobin was easily separated as pale yellow precipitates following solvent concentration and cooling (Fig.-2A). Recrystallization and washing with cold methanol of the yellowish crystals yielded colorless crystals (Fig.-2B).

A

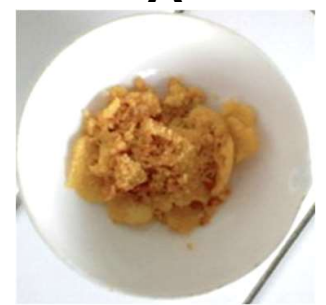

B

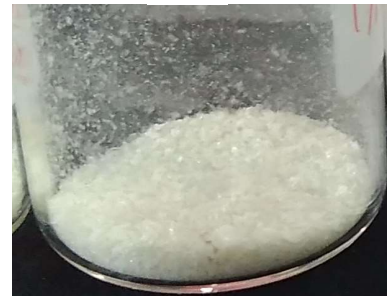<smiles>COc1cc(O)c2c(c1)O[C@H](c1ccccc1)CC2=O</smiles>

Fig.-2. Pinostrobin crystals isolated from $B$. rotunda rhizome. (A) Pale yellow precipitates of pinostrobin were obtained from the concentrated petroleum ether extract of $B$. rotunda rhizome. (B) Purified colorless crystals of pinostrobin. (C) Chemical structure of pinostrobin.

Through this simple protocol, we were able to isolate pinostrobin with $\geq 99 \%$ purity and $2.36 \%$ yield. The TLC analysis (Fig.-3A) showed the presence of a single spot in four different mobile phases with distinct polarity, indicating that the isolated pinostrobin is pure. The $\geq 99 \%$ purity was confirmed by HPLC analysis (Fig.-3B) and was equal to that of commercial pinostrobin $(\geq 99 \%){ }^{27}$

The structure of the isolated pinostrobin was confirmed using UV and IR spectrophotometers, with the following results: $\mathrm{UV}=289.50 \mathrm{~nm}$; $\mathrm{IR}(\mathrm{KBr}) v_{\max } \mathrm{in}^{-1}=2,973.3(\mathrm{CH}), 1,646.4(\mathrm{C}=\mathrm{O}$ and $\mathrm{C}=\mathrm{C}), 1,444.5$ 
RASĀYAN J. Chem.

Vol. 14 | No. 2 |735-740| April - June | 2021

$\left(\mathrm{CH}_{2}\right), 1,381.5\left(\mathrm{CH}_{3}\right), 1,302.9(\mathrm{C}-\mathrm{O})$, and 1,210.1 and 1,159.1 (C-O-C). The interpretation of the ${ }^{1} \mathrm{H}-\mathrm{NMR}$ and ${ }^{13} \mathrm{C}$-NMR spectra is presented in Table-1. All of the obtained spectra were consistent with those previously reported, ${ }^{28,29}$ confirming the structural similarity. In summary, this non-chromatographic method was proven to be an effective and efficient technique capable of isolating pinostrobin from $B$. rotunda rhizome with high yield without sacrificing its purity.
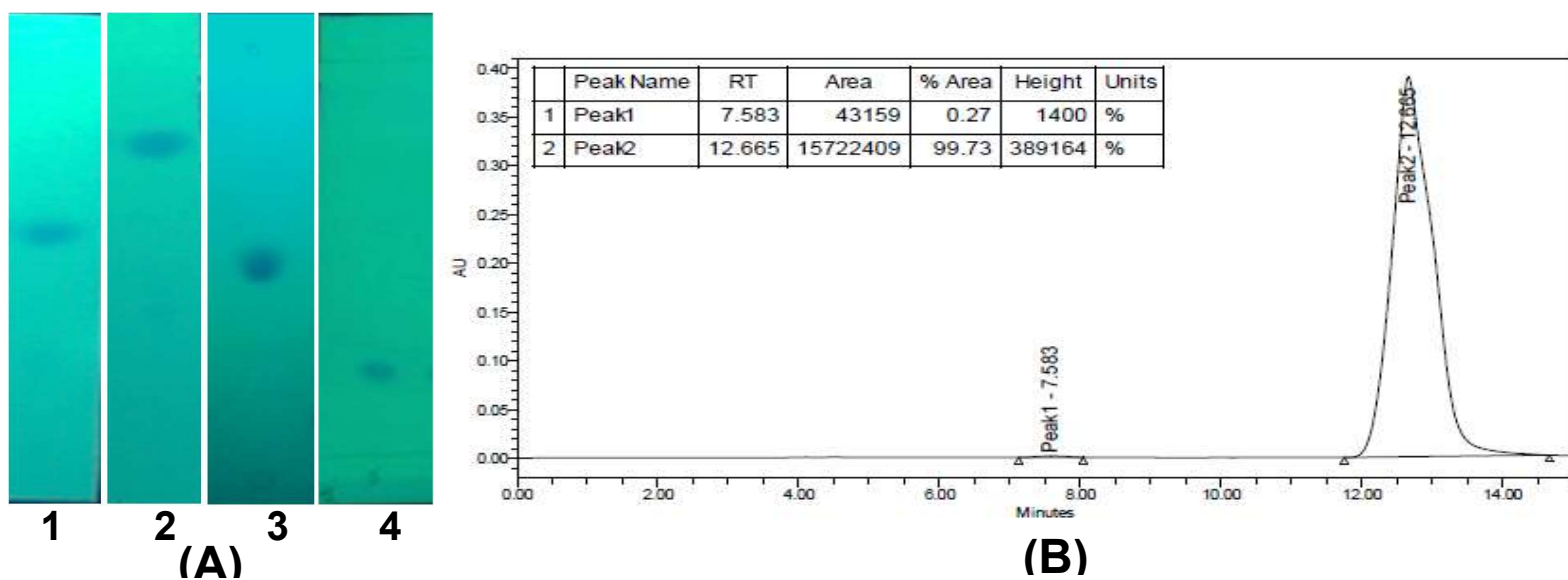

(B)

Fig.-3: Purity analysis of the isolated pinostrobin. (A) TLC profiles of the isolated pinostrobin. The TLC analysis was conducted on silica gel F254 with the mobile phases of $n$-hexane/ethyl acetate (4:1), $n$-hexane/ethanol (7:1), petroleum ether/ethyl acetate (5:1), and $n$-hexane/chloroform $(3: 1)$ denoted by numbers $1,2,3$, and 4 , respectively, detected at UV254 nm. (B) HPLC profile of the isolated pinostrobin. The isolated pinostrobin showed a purity of 99.73\%. The HPLC conditions were as follows: column: C18 Xterra $(5 \mu \mathrm{m}, 150 \mathrm{~mm} \times 780 \mathrm{~mm}$ i.d. $)$; mobile phase: methanol/water (80:20); detector: PDA at $254 \mathrm{~nm}$; and flow rate $=1 \mathrm{~mL} / \mathrm{min}$.

Table-1: ${ }^{1} \mathrm{H}-\mathrm{NMR}$ and ${ }^{13} \mathrm{C}-\mathrm{NMR}$ Spectral Data (in $\mathrm{CDCl}_{3}$ ) compared with those of a Previous Study ${ }^{28}$

\begin{tabular}{|c|c|c|c|c|}
\hline \multirow{2}{*}{$\begin{array}{c}\text { Position } \\
\text { of } \\
\text { Carbon }\end{array}$} & \multicolumn{2}{|l|}{ Data } & \multicolumn{2}{|l|}{ Reference $^{28}$} \\
\hline & $\begin{array}{c}{ }^{1} \mathrm{H}-\mathrm{NMR} \delta\left(\sum \mathrm{H} ; \mathrm{m} ; \mathrm{J} \mathrm{Hz}\right) \\
\quad\left(400 \mathrm{MHz}, \mathrm{CDCl}_{3}\right)\end{array}$ & $\begin{array}{c}{ }^{13} \mathrm{C}-\mathrm{NMR} \delta \\
(\mathrm{ppm})(100 \\
\mathrm{MHz} \\
\left.\mathrm{CDCl}_{3}\right)\end{array}$ & $\begin{array}{c}{ }^{1} \mathrm{H}-\mathrm{NMR} \delta\left(\sum \mathrm{H} ; \mathrm{m} ; \mathrm{J} \mathrm{Hz}\right) \\
\left(300 \mathrm{MHz}, \mathrm{DMSO}-\mathrm{d}_{6}\right)\end{array}$ & 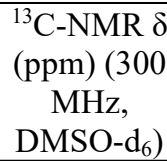 \\
\hline 1 & - & & - & - \\
\hline 2 & $5.42(1 \mathrm{H}, \mathrm{dd}, 12.8 ; 3.2, \mathrm{H}-2)$ & 79.42 & $5.44(1 \mathrm{H}, \mathrm{dd}, 12.7 ; 3.1, \mathrm{H}-2)$ & 79.44 \\
\hline \multirow[t]{2}{*}{3} & $\begin{array}{l}3.07(1 \mathrm{H}, \mathrm{dd}, 17.2 ; 12.8, \mathrm{H}- \\
3 \mathrm{ax})\end{array}$ & 43.57 & $3.48(1 \mathrm{H}, \mathrm{dd}, 17.1 ; 12.7, \mathrm{H}-3 \mathrm{ax})$ & 43.03 \\
\hline & $\begin{array}{l}2.83(1 \mathrm{H}, \mathrm{dd}, 17.2 ; 3.2, \mathrm{H}- \\
3 \mathrm{eq})\end{array}$ & & $2.84(1 \mathrm{H}, \mathrm{dd}, 17.1 ; 3.1, \mathrm{H}-3 \mathrm{eq})$ & \\
\hline 4 & - & 195.99 & - & 196.60 \\
\hline 5 & - & 164.29 & - & 164.10 \\
\hline 6 & $6.06(1 \mathrm{H}, \mathrm{d}, 2.4, \mathrm{H}-6)$ & 95.30 & $6.10(1 \mathrm{H}, \mathrm{d}, 2.3 \mathrm{~Hz}, \mathrm{H}-6)$ & 94.80 \\
\hline 7 & - & 168.15 & - & 168.36 \\
\hline 8 & $6.06(1 \mathrm{H}, \mathrm{d}, 2.4, \mathrm{H}-8)$ & 94.44 & $6.15(1 \mathrm{H}, \mathrm{d}, 2.3 \mathrm{~Hz}, \mathrm{H}-8)$ & 95.66 \\
\hline 9 & - & 162.95 & - & 163.52 \\
\hline 10 & - & 103.30 & - & 103.52 \\
\hline $1^{\prime}$ & - & 138.50 & - & 139.41 \\
\hline $2^{\prime}$ & $7.45\left(1 \mathrm{H}, \mathrm{m}, \mathrm{H}-2^{\prime}\right)$ & 126.32 & $7.55\left(1 \mathrm{H}, \mathrm{m}, \mathrm{H}-2^{\prime}\right)$ & 127.51 \\
\hline $3^{\prime}$ & $7.42\left(1 \mathrm{H}, \mathrm{m}, \mathrm{H}-3^{\prime}\right)$ & 129.07 & $7.43\left(1 \mathrm{H}, \mathrm{m}, \mathrm{H}-3^{\prime}\right)$ & 129.43 \\
\hline $4^{\prime}$ & $7.42\left(1 \mathrm{H}, \mathrm{m}, \mathrm{H}-4^{\prime}\right)$ & 129.07 & $7.43\left(1 \mathrm{H}, \mathrm{m}, \mathrm{H}-4^{\prime}\right)$ & 129.49 \\
\hline $5^{\prime}$ & $7.42\left(1 \mathrm{H}, \mathrm{m}, \mathrm{H}-5^{\prime}\right)$ & 129.07 & $7.43\left(1 \mathrm{H}, \mathrm{m}, \mathrm{H}-5^{\prime}\right)$ & 129.43 \\
\hline $6^{\prime}$ & $7.45\left(1 \mathrm{H}, \mathrm{m}, \mathrm{H}-6^{\prime}\right)$ & 126.32 & $7.55\left(1 \mathrm{H}, \mathrm{m}, \mathrm{H}-6^{\prime}\right)$ & 127.51 \\
\hline $5-\mathrm{OH}$ & $12.01(1 \mathrm{H}, \mathrm{s}, 5-\mathrm{OH})$ & - & $12.10(1 \mathrm{H}, \mathrm{s}, 5-\mathrm{OH})$ & - \\
\hline $7-\mathrm{OCH}_{3}$ & $3.80\left(3 \mathrm{H}, \mathrm{s}, 7-\mathrm{OCH}_{3}\right)$ & 55.90 & $3.81\left(3 \mathrm{H}, \mathrm{s}, 7-\mathrm{OCH}_{3}\right)$ & 56.57 \\
\hline
\end{tabular}


RASĀYAN J. Chem.

Vol. 14 | No. 2 |735-740| April - June | 2021

\section{CONCLUSION}

In this study, we developed a simple, fast, and inexpensive non-chromatographic method to isolate pinostrobin from $B$. rotunda rhizome with high purity and yield.

\section{ACKNOWLEDGEMENT}

This study was supported by the Direktorat Jenderal Bina Kefarmasian dan Alat Kesehatan, Kementrian Kesehatan RI (Grant number HK.02.03/V/840/2015). The data in this study was used by Oktariani Pramiastuti for her master thesis.

\section{REFERENCES}

1. N. K. Patel, G. Jaiswal and K. K. Bhutani, Natural Product Research, 30(18), 2017(2016), DOI: $10.1080 / 14786419.2015 .1107556$

2. R. I. Depkes, Indonesin Herbal Pharmacopeia 1st edition [Farmakope herbal Indonesia Edisi 1]. (Kementrian Kesehatan Republik Indonesia, Jakarta, 2008).

3. M. Ibrahim Awad, A. Muhammad Nadeem, B. Foo Jhi, T. Yin Sim, Z. Seema, S. Sakina Binti, H. Hazrulrizawati Binti Abd, H. Zaheer Ul, K. Ruqaiya and K. Reem Maan, The Natural Products Journal, 9(4), 341(2019), DOI: 10.2174/2210315509666190117151542

4. N. K. Patel and K. K. Bhutani, Phytomedicine: InternationalJjournal of Phytotherapy and Phytopharmacology, 21(7), 946(2014), DOI: 10.1016/j.phymed.2014.02.011

5. W. A. R. Junior, D. B. Gomes, B. Zanchet, A. P. Schönell, K. A. P. Diel, T. P. Banzato, A. L. T. G. Ruiz, J. E. Carvalho, A. Neppel, A. Barison and C. A. M. Santos, Revista Brasileira de Farmacognosia 27(5), 592(2017), DOI:10.1016/j.bjp.2017.05.007

6. J. Ramirez, L. Cartuche, V. Morocho, S. Aguilar and O. Malagon, Revista Brasileira de Farmacognosia, 23(2), 370(2013), DOI:10.1590/S0102-695X2013005000012

7. J. W. Fahey and K. K. Stephenson, Journal of Agricultural and Food Chemistry, 50 (25), 7472(2002), DOI: $10.1021 / \mathrm{jf0} 25692 \mathrm{k}$

8. J. Granados-Pineda, N. Uribe-Uribe, P. García-López, M. D. P. Ramos-Godinez, J. F. Rivero-Cruz and J. M. Pérez-Rojas, Molecules, 23(4), 852(2018), DOI:10.3390/molecules23040852

9. B. C. Tan, S. K. Tan, S. M. Wong, N. Ata, N. A. Rahman and N. Khalid, Evidence-Based Complementary and Alternative Medicine, 2015, 451870(2015), DOI:10.1155/2015/451870

10. O. Ongwisespaiboon and W. Jiraungkoorskul, Pharmacognosy Reviews, 11(21), 27(2017), DOI: $10.4103 /$ phrev.phrev_50_16

11. A. Chahyadi, R. Hartati, K. R. Wirasutisna and Elfahmi, Procedia Chemistry 13, 13(2014), DOI: $10.1016 /$ j.proche.2014.12.003

12. N. N. Win, S. Awale, H. Esumi, Y. Tezuka and S. Kadota, Journal of Natural Products, 70(10), 1582(2007), DOI: 10.1021/np070286m

13. T. Potipiranun, S. Adisakwattana, W. Worawalai, R. Ramadhan and P. Phuwapraisirisan, Molecules, 23(12), 3365(2018), DOI:10.3390/molecules23123365

14. S. I. Abdelwahab, S. Mohan, M. A. Abdulla, M. A. Sukari, A. B. Abdul, M. M. E. Taha, S. Syam, S. Ahmad and K.-H. Lee, Journal of Ethnopharmacology, 137(2), 963(2011), DOI:10.1016/j.jep.2011.07.010

15. K. Yuan, Y. Liu, Z. Zhang, L. Yuanhui, Y. Ke and Z. Zhijun, China Patent, CN104286034A (2009),https://patents.google.com/patent/CN104286034A/en

16. L.-L. Wang, Y.-B. Zhang, X.-Y. Sun and S.-Q. Chen, Journal of Liquid Chromatography \& Related Technologies, 39(8), 422(2016), DOI:10.1080/10826076.2016.1169429

17. R. Rosmelia, B. E. Suryaningsih, H. Anshory and Y. W. Wirohadidjojo, Jurnal Kedokteran dan Kesehatan Indonesia, 7(4), 137(2016), DOI:10.20885/JKKI.Vol7.Iss4.art4

18. M. Lingyuan, China Patent, CN101875648A (2010), https://patents.google.com/patent/CN101875648A/en

19. A. Ching, T. Wah, M. Sukari, G. Lian, M. Rahmani and K. Khalid, The Malaysian Journal of Analytical Sciences, 11(1), 154(2007)

20. C. Liyan, F. Yujie, K. Yu, L. Qingyong, L. Wei, L. Xia, L. Meng, T. Meihong, Z. Lin and Z. Yuangang, China Patent, CN101172948B (2007), https://patents.google.com/patent/CN101172948B/en 
RASĀYAN J. Chem.

Vol. 14 | No. 2 |735-740| April - June | 2021

21. T. Eng-Chong, L. Yean-Kee, C. Chin-Fei, H. Choon-Han, W. Sher-Ming, C. T. Li-Ping, F. Gen-Teck, N. Khalid, N. Abd Rahman, S. A. Karsani, S. Othman, R. Othman and R. Yusof, Evidence-Based Complementary and Alternative Medicine, 2012, 473637(2012), DOI:10.1155/2012/473637

22. S. Subramaniam, R. Raju, A. Palanisamy and A. Sivasubramanian, Pharmacognosy Magazine, 11(42), 127(2015), DOI: 10.4103/0973-1296.157714

23. A. Nix, C. A. Paull and M. Colgrave, SpringerPlus, 4(1), 125(2015), DOI:10.1186/s40064-015-0906$\mathrm{X}$

24. L. Pobłocka-Olech, P. Migas and M. Krauze-Baranowska, Acta Pharmaceutica, 68(2), 199(2018), DOI: $10.2478 /$ acph-2018-0018

25. I. Montes, C. Lai and D. Sanabria, Journal of Chemical Education, 80(4), 447(2003), DOI: $10.1021 / \mathrm{ed} 080 \mathrm{p} 447$

26. C. L. Sayre, S. Alrushaid, S. E. Martinez, H. D. Anderson and N. M. Davies, Journal of Pharmacy \& Pharmaceutical Sciences : A Publication of the Canadian Society for Pharmaceutical Sciences, 18 (4), 368(2015), DOI: 10.18433/j3bk5t

27. W. C. N. Biotech, L. Wuhan(Ed.), Vol.2020, ChemNorm Biotech Co. (Wuhan, China, 2020)

28. H. D. Smolarz, E. Mendyk, A. Bogucka-Kocka and J. Kocki, Zeitschrift für Naturforschung, C61(1-2), 64(2006), DOI:10.1515/znc-2006-1-212

29. O. Pramiastuti, Master Thesis, Faculty of Pharmacy, Universaitas Gadjah Mada, Yogyakarta, Indonesia (2016).

[RJC-6146/2020] 